\title{
Exigências de treonina digestível para leitoas mantidas em ambiente termoneutro dos 15 aos $30 \mathrm{~kg}^{1}$
}

\section{Edilson Paes Saraiva ${ }^{2}$, Rita Flávia Miranda de Oliveira $^{3}$, Juarez Lopes Donzele ${ }^{3}$, Francisco Carlos de Oliveira Silva ${ }^{4}$, Jefferson Costa de Siqueira ${ }^{2}$, Maria Cristina Manno ${ }^{2}$, Will Pereira de Oliveira ${ }^{5}$, Christiane Garcia Vilela Nunes ${ }^{2}$}

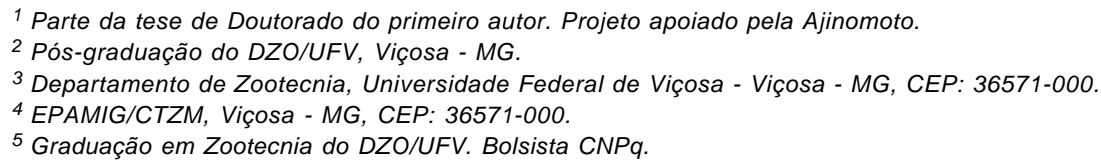

RESUMO - Este estudo foi conduzido com o objetivo de avaliar as exigências de treonina digestível em rações para leitoas

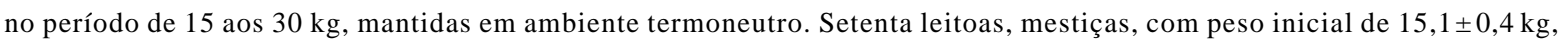
foram distribuídas em delineamento experimental de blocos ao acaso, com cinco tratamentos (níveis de treonina digestível), sete repetições e dois animais por unidade experimental. Os tratamentos corresponderam aos níveis de 0,$54 ; 0,58 ; 0,61 ; 0,65$ e $0,69 \%$ de treonina digestível. Os níveis de treonina digestível da ração aumentaram o ganho de peso diário de forma quadrática até o nível de $0,61 \%$ e a conversão alimentar até o nível de $0,62 \%$. As deposições de proteína e gordura na carcaça dos animais também se elevaram de forma quadrática, atingindo valor máximo no nível de 0,61\%. Constatou-se efeito linear dos tratamentos sobre os pesos absoluto e relativo do intestino. O nível calculado de $0,62 \%$ de treonina digestível, correspondente a uma relação com a lisina digestível de $67 \%$ e a um consumo diário de $7,11 \mathrm{~g}$, proporcionou melhor desempenho de leitoas mantidas em ambiente termoneutro dos 15 aos $30 \mathrm{~kg}$.

Palavras-chave: desempenho, relação treonina digestível:lisina digestível, temperatura ambiente

\section{Digestible threonine requirement for gilts maintained in thermoneutral environment from 15 to $30 \mathrm{~kg}$}

\begin{abstract}
This study was carried out to evaluate the requirements of digestible threonine in diets of gilts from 15 to $30 \mathrm{~kg}$, maintained in thermoneutral environment. Seventy crossbreed gilts with an initial weight of $15.1 \pm 0.4 \mathrm{~kg}$ were used in a randomized blocks design, with five treatments (levels of digestible threonine), seven replicates and two animals per experimental unity. The treatments corresponded to the levels of $0.54,0.58,0.61,0.65$, e $0.698 \%$ of digestible threonine. Digestible threonine levels in the diet increased the daily weight gain in a quadratic way up to the level of $0.61 \%$ and the feed:gain ratio up to the level of $0.62 \%$. Protein and fat deposition rates also increased in a quadratic way reaching maximum value up to the level of $0.61 \%$. A linear effect of the treatments was evidenced on the absolute and relative weights of the intestine. The calculated level of $0.62 \%$ of digestible threonine corresponding to a relation with digestible lysine of $67 \%$ and a daily intake of $7.11 \mathrm{~g}$, provided better performance of gilts maintained in a thermoneutral environment from 15 to $30 \mathrm{~kg}$.
\end{abstract}

Key Words: environmental temperature, digestible threonine:digestible lysine ratio, performance

\section{Introdução}

As principais características do suíno atual - alto potencial de deposição de carne magra, baixo consumo e maior exigência nutricional - exigem melhores ajustes na formulação das rações, as quais, durante muitos anos, foram feitas com base no ingrediente mais caro, a proteína bruta.

De acordo com Stahley (1993), o excesso de aminoácidos na dieta reduz a energia disponível para crescimento, pois parte dessa é utilizada na degradação dos produtos nitrogenados. A ingestão de rações deficientes em aminoácidos, por outro lado, diminui a taxa de crescimento. Em ambas as situações, o desequilíbrio entre os aminoácidos essenciais e não-essenciais produz efeitos adversos no desempenho do suíno.

Em razão dos problemas com poluição ambiental, tem-se reduzido a quantidade de proteína nas rações fornecidas aos suínos (Pedersen et al., 2003). Com esta prática, a determinação da correta proporção dos 
aminoácidos na proteína tornou-se fundamental para garantir o bom desempenho dos animais.

Entre os aminoácidos a serem avaliados, destaca-se a treonina, por ser, normalmente, o segundo ou terceiro aminoácido limitante nas dietas à base de cereais e farelo de soja fornecidas aos suínos (Lewis, 2001). Segundo Saldana et al. (1994), a treonina pode se tornar o primeiro aminoácido limitante quando a lisina industrial é adicionada à dieta.

Considerando a possibilidade de variação das exigências nutricionais de aminoácidos pelo suíno, é fundamental a determinação das exigências desses nutrientes, em função do ambiente térmico, sobretudo quando se visa à alimentação econômica e tecnicamente mais viável.

Este estudo foi conduzido para avaliar níveis de treonina digestível em rações para leitoas mantidas em ambiente termoneutro dos 15 aos $30 \mathrm{~kg}$.

\section{Material e Métodos}

O experimento foi conduzido em salas climatizadas no Setor de Suinocultura do Departamento de Zootecnia, do Centro de Ciências Agrárias, da Universidade Federal de Viçosa, em Viçosa, MG.

Setenta leitoas mestiças (Landrace x Large White), com peso inicial de $15,1 \pm 0,42 \mathrm{~kg}$, foram distribuídas em delineamento experimental de blocos ao acaso, com cinco tratamentos $(0,538 ; 0,577 ; 0,614 ; 0,651$ e $0,688 \%$ de treonina digestível), sete repetições e dois animais por unidade experimental, mantidos em ambiente de conforto térmico. $\mathrm{Na}$ formação dos blocos, considerou-se o peso inicial dos animais.

Os animais, em grupo de dois, foram alojados em gaiolas metálicas suspensas $(1,65 \mathrm{~m} \times 1,10 \mathrm{~m})$, com piso ripado, providas de comedouro semi-automático e bebedouro tipo chupeta. Essas gaiolas foram mantidas em sala de alvenaria com janelas de vidro do tipo basculante, cobertura de telha de barro e forro de madeira e controle de temperatura e umidade relativa.

A temperatura e a umidade relativa internas da sala foram monitoradas três vezes ao dia $(8,13$ e 17 h) durante o período experimental.

Os equipamentos de medição ambiental (termômetros de máxima e mínima, de bulbo seco e bulbo úmido e de globo negro) foram mantidos em uma gaiola vazia, no centro da sala, à meia altura do corpo dos animais. Os valores obtidos de temperatura e umidade foram, posteriormente, convertidos no índice de temperatura de globo e umidade (ITGU), segundo Buffington et al. (1981), caracterizando-se o ambiente térmico em que os animais foram mantidos.
As rações experimentais (Tabela 1), à base de milho, farelo de soja, glúten de milho e amido, foram formuladas para serem isoenergéticas e isolisínicas e suplementadas com minerais, vitaminas e aminoácidos, de acordo com as recomendações contidas em Rostagno et al. (2000), com exceção da treonina. A inclusão de L-treonina ocorreu em substituição ao ácido glutâmico, com base nos seus equivalentes protéicos, sendo o amido utilizado para compensar as diferenças de equivalência em peso.

Durante o experimento, os animais receberam ração e água à vontade.

Os resíduos de ração no chão foram coletados diariamente e somados às sobras do comedouro, para determinação do consumo de ração no final do período experimental.

No final do período experimental $(24 \pm 1,8$ dias $)$, os animais foram submetidos a jejum alimentar de 24 horas, abatendo-se um animal de cada unidade experimental com o peso mais próximo de $30 \mathrm{~kg}$. Retiraram-se o fígado, os rins e o intestino para pesagem.

As carcaças inteiras (incluindo cabeça e pés), evisceradas e sem sangue, foram pesadas e cortadas longitudinalmente. A metade direita de cada carcaça foi triturada em "cutter" comercial de $30 \mathrm{HP}$ e $1.775 \mathrm{rpm}$, durante 15 minutos. Após homogeneização do material triturado, foram retiradas amostras, que foram congeladas para determinação das deposições de proteína e gordura, conforme metodologia descrita em Donzele et al. (1992).

Para determinação da composição inicial das carcaças e das deposições de proteína e gordura na carcaça, foi utilizada a técnica do abate comparativo. Para isso, um grupo adicional de cinco leitoas com peso médio de $15 \mathrm{~kg}$ foi abatido no início do experimento. Adotaram-se os mesmos procedimentos de abate dos animais utilizados no final do experimento.

No preparo das amostras, em razão do alto teor de água e gordura do material, procedeu-se à pré-secagem em estufa com ventilação forçada, por 72 horas a $\pm 60^{\circ} \mathrm{C}$, e ao pré-desengorduramento a quente, em aparelho extrator do tipo "Soxhlet", durante quatro horas. As amostras présecas e pré-desengorduradas foram moídas e acondicionadas para posteriores análises laboratoriais. Para correção dos valores das análises subseqüentes, foram consideradas a água e a gordura retiradas no preparo das amostras.

As análises de PB e EE dos ingredientes das rações e das carcaças foram realizadas no Laboratório de Nutrição Animal do Departamento de Zootecnia da UFV, conforme técnicas descritas em Silva (1990).

As análises estatísticas das variáveis avaliadas (desempenho, pesos de órgãos e deposições na carcaça) foram realizadas por meio do programa computacional Sis temas de Análises Estatísticas e Genéticas (SAEG, 1997). 
Tabela 1 - Composições centesimal e calculada das rações experimentais

Table 1 - Percentage and calculated compositions of the experimental diets

\begin{tabular}{|c|c|c|c|c|c|}
\hline \multirow{3}{*}{$\begin{array}{l}\text { Ingrediente (\%) } \\
\text { Ingredient }\end{array}$} & \multirow{2}{*}{\multicolumn{5}{|c|}{$\begin{array}{c}\text { Nível de treonina digestível (\%) } \\
\text { Digestible threonine level }\end{array}$}} \\
\hline & & & & & \\
\hline & 0,538 & 0,577 & 0,614 & 0,651 & 0,688 \\
\hline Milho grão (Corn) $(8,74 \%)^{*}$ & 72,823 & 72,823 & 72,823 & 72,823 & 72,823 \\
\hline Farelo de soja (Soybean meal) $(45,42 \%) *$ & 18,745 & 18,745 & 18,745 & 18,745 & 18,745 \\
\hline Glúten de milho (Corn gluten) $(61,3 \%)^{*}$ & 3,500 & 3,500 & 3,500 & 3,500 & 3,500 \\
\hline Amido (Starch) & 0,155 & 0,166 & 0,176 & 0,184 & 0,195 \\
\hline Fosfato bicálcico (Dicalcium phosphate) & 1,792 & 1,792 & 1,792 & 1,792 & 1,792 \\
\hline Calcário (Limestone) & 0,785 & 0,785 & 0,785 & 0,785 & 0,785 \\
\hline Mistura mineral (Mineral mix $)^{1}$ & 0,100 & 0,100 & 0,100 & 0,100 & 0,100 \\
\hline Mistura vitamínica (Vitamin mix) $)^{2}$ & 0,100 & 0,100 & 0,100 & 0,100 & 0,100 \\
\hline Sal comum (Salt) & 0,366 & 0,366 & 0,366 & 0,366 & 0,366 \\
\hline Óleo de soja (Soybean oil) & 0,500 & 0,500 & 0,500 & 0,500 & 0,500 \\
\hline Antibiótico (Antibiotic) & 0,100 & 0,100 & 0,100 & 0,100 & 0,100 \\
\hline BHT & 0,010 & 0,010 & 0,010 & 0,010 & 0,010 \\
\hline Glut & 0,590 & 0,536 & 0,485 & 0,436 & 0,384 \\
\hline L-lys & 0,381 & 0,381 & 0,381 & 0,381 & 0,381 \\
\hline L-thr & - & 0,043 & 0,084 & 0,125 & 0,166 \\
\hline L-trp & 0,028 & 0,028 & 0,028 & 0,028 & 0,028 \\
\hline DL-met & 0,025 & 0,025 & 0,025 & 0,025 & 0,025 \\
\hline \multicolumn{6}{|l|}{ Composição calculada ${ }^{3}$} \\
\hline \multicolumn{6}{|l|}{ Calculated composition } \\
\hline $\mathrm{PB}(C P)(\%)$ & 17,6 & 17,6 & 17,6 & 17,6 & 17,6 \\
\hline $\mathrm{ED}(D E)(\mathrm{kcal} / \mathrm{kg})$ & 3.400 & 3.400 & 3.400 & 3.400 & 3.400 \\
\hline Lys total $(\%)$ & 1,037 & 1,037 & 1,037 & 1,037 & 1,037 \\
\hline Lys digestível (Digestible lys) (\%) & 0,930 & 0,930 & 0,930 & 0,930 & 0,930 \\
\hline Thr total (Total thr) $(\%)$ & 0,648 & 0,690 & 0,731 & 0,772 & 0,812 \\
\hline Thr digestível (\%) (Digestible thr) (\%) & 0,538 & 0,577 & 0,614 & 0,651 & 0,688 \\
\hline Met + cys digestível (Digestible met + cys) $(\%)$ & 0,558 & 0,558 & 0,558 & 0,558 & 0,558 \\
\hline Met digestível (Digestible met) $(\%)$ & 0,251 & 0,251 & 0,251 & 0,251 & 0,251 \\
\hline Trp digestível (Digestible trp) (\%) & 0,177 & 0,177 & 0,177 & 0,177 & 0,177 \\
\hline Val digestível(Digestible val) (\%) & 0,681 & 0,681 & 0,681 & 0,681 & 0,681 \\
\hline $\mathrm{Ca}(\%)$ & 0,830 & 0,830 & 0,830 & 0,830 & 0,830 \\
\hline $\mathrm{P}$ total $($ Total $P)(\%)$ & 0,629 & 0,629 & 0,629 & 0,629 & 0,629 \\
\hline $\mathrm{P}$ disponível(Available P) (\%) & 0,430 & 0,430 & 0,430 & 0,430 & 0,430 \\
\hline
\end{tabular}

* Valores determinados no Laboratório de Nutrição Animal - DZO/UFV (Values determined at Lab of Animal Nutrition - DZO/UFV).

1 Contém em $1 \mathrm{~kg}$ (Contents/kg): Fe, $100 \mathrm{~g}$; Cu, $10 \mathrm{~g}$; Co, $1 \mathrm{~g} ; \mathrm{Mn}, 40 \mathrm{~g} ; \mathrm{Zn}, 100 \mathrm{~g} ; \mathrm{I}, 1,5 \mathrm{~g}$; e excipiente (excipient) q.s.p., $1000 \mathrm{~g}$

${ }^{2}$ Contém em $1 \mathrm{~kg}$ (Contents/kg): vit. A, 6.000 .000 UI; vit. $\mathrm{D}_{3}, 1.500 .000$ UI; vit. $\mathrm{E}, 15.000 .000 \mathrm{UI}$; vit. $\mathrm{B}_{1}, 1,35 \mathrm{~g}$; vit. $\mathrm{B}_{2}, 4 \mathrm{~g} ;$ vit. $\mathrm{B}_{6}, 2 \mathrm{~g}$; ácido pantotênico (pantothenic acid), 9,35 g; vit. $\mathrm{K}_{3}, 1,5 \mathrm{~g}$; ácido nicotínico (nicotinic acid), 20,0 g; vit. B12, $20,0 \mathrm{~g}$; ácido fólico (pholicacid), 0,6 g; biotina (biotin), 0,08 g; Se, 0,3g; e excipiente (and excipient) q. s. p., $1000 \mathrm{~g}$.

${ }^{3}$ Composição calculada segundo Rostagno et al. (2000), com exceção da treonina digestível (Calculated composition according to Rostagno et al., 2000, except for digestible threonine).

A estimativa da exigência de treonina digestível foi feita com base nos resultados de desempenho e carcaça, utilizando-se os modelos linear, quadrático e, ou, descontínuo "Linear Response Plateau" (LRP), descritos por Braga (1983), conforme melhor ajuste obtido de cada variável.

\section{Resultados e Discussão}

Durante o período experimental, a temperatura interna da sala manteve-se em $22,0 \pm 0,8^{\circ} \mathrm{C}$ e a umidade relativa em $78,1 \pm 5,7 \%$ e o índice de temperatura de globo e umidade (ITGU) foi calculado em 70,0 $\pm 1,4$.

Os níveis de treonina digestível da ração propiciaram resposta quadrática $(\mathrm{P}<0,05)$ n o ganho de peso diário $(\mathrm{GPD})$, que aumentou até o nível de $0,606 \%$ (Figura 1a). Variação significativa do ganho de peso de leitões em fase inicial de crescimento, em razão do aumento do nível de treonina da ração, também foi observada por Lewis \& Peo Jr. (1986), Saldana et al. (1994) e Berto et al. (2002), que estimaram, respectivamente, em 0,$83 ; 0,69$ e $0,76 \%$ os níveis de treonina total como o de máximo ganho de peso. Por outro lado, Pozza et al. (1999), avaliando o efeito de níveis crescentes de treonina sobre o desempenho de leitões dos 15 aos $30 \mathrm{~kg}$, não observaram efeito dos tratamentos sobre o ganho de peso diário dos animais (Tabela 2). As variações nas condições experimentais, especialmente no que se refere à genética dos animais e aos ingredientes utilizados nas rações, podem, entre outros fatores, justificar a variação dos resultados. 
Tabela 2 - Desempenho e deposição de gordura e proteína na carcaça de leitoas dos 15 aos 30 kg, mantidas em ambiente termoneutro, em função do nível de treonina digestível da ração

Table 2 - Performance and fat and protein deposition in the carcass of gilts from 15 to $30 \mathrm{~kg}$ kept in thermoneutral environment in function of digestible threonine level in diet

\begin{tabular}{|c|c|c|c|c|c|c|}
\hline \multirow[t]{2}{*}{ Item } & \multicolumn{5}{|c|}{$\begin{array}{c}\text { Nível de treonina digestível (\%) } \\
\text { Digestible threonine level }\end{array}$} & \multirow[t]{2}{*}{$\mathrm{CV}(\%)$} \\
\hline & 0,538 & 0,577 & 0,614 & 0,651 & 0,688 & \\
\hline Ganho de peso $(\mathrm{g} / \mathrm{d})^{1}$ (Weight gain) & 603 & 647 & 637 & 606 & 601 & 7,7 \\
\hline Consumo de ração (g/d) (Feed intake) & 1.140 & 1.202 & 1.151 & 1.127 & 1.129 & 4,8 \\
\hline Conversão alimentar $(\mathrm{g} / \mathrm{g})^{2}$ (Feed: gain ratio) & 1,89 & 1,86 & 1,81 & 1,86 & 1,88 & 3,8 \\
\hline Consumo de Thr dig. $(\mathrm{g} / \mathrm{d})^{4}$ (Digestible Thr intake) & 6,1 & 6,9 & 7,1 & 7,3 & 7,8 & 4,6 \\
\hline \multicolumn{7}{|l|}{ Deposição na carcaça (g/d) (Carcass deposition) } \\
\hline Proteína ${ }^{3}$ (Protein) & 68 & 78 & 73 & 72 & 68 & 8,9 \\
\hline Gordura $^{3}$ (Fat) & 81 & 95 & 91 & 91 & 79 & 8,9 \\
\hline
\end{tabular}

1,2 e 3 Efeito quadrático $(P<0,05),(P<0,10)$ e $(P<0,01)$, respectivamente (Quadratic effect $[P<0.05][P<0.10]$ and $[P<0.01]$, respectively)

${ }^{4}$ Efeito linear $(P<0,01)$ (Linear effect, $\left.P<0.01\right)$.

No nível em que se estimou a melhor resposta de ganho de peso $(0,606 \%)$, a relação treonina digestível:lisina digestível calculada correspondeu a $65 \%$, semelhante à recomendação de Rostagno et al. (2000). Assim, de acordo com Berto et al. (2002), o nível de lisina das rações não pode ser superior ao exigido pelos animais, devendo-se respeitar as proporções entre esse aminoácido e os demais, principalmente os limitantes, e considerar o conceito da proteína ideal.

Não houve efeito $(P>0,10)$ dos níveis de treonina sobre o consumo de ração diário (CRD), enquanto o consumo de treonina aumentou $(\mathrm{P}<0,01)$ de forma linear segundo a equação: $\hat{Y}=0,82634+10,1207 X\left(r^{2}=0,97\right)$. Resultados similares foram obtidos por Lewis \& Peo Jr. (1986) e Borg et al. (1987), em suínos jovens. No entanto, Saldana et al. (1994), Pozza et al. (1999) e Rodrigues et al. (2001) observaram aumento e Rosell \& Zimmerman (1985), redução linear no consumo de ração, em função de níveis crescentes de treonina da ração.

Os diferentes padrões de resposta de consumo de ração dos suínos, em razão da variação do nível de treonina, podem estar relacionados, entre outros fatores, a diferenças nos níveis deste aminoácido utilizados nas rações experimentais.

Foi verificado efeito $(\mathrm{P}<0,10)$ quadrático dos níveis de treonina digestível sobre a conversão alimentar (CA), que melhorou até o nível estimado de $0,621 \%$ de treonina digestível (Figura 1b). Este resultado corrobora o de 0,63\% recomendado pelo NRC (1998) e situa-se acima daquele de $0,60 \%$ recomendado por Rostagno et al. (2000), para suínos dos 10 aos $20 \mathrm{~kg}$.

A exigência de treonina determinada pela $\mathrm{CA}$, neste trabalho, pode estar relacionada ao efeito quadrático dos níveis de treonina sobre o GPD, uma vez que não houve efeito significativo $(\mathrm{P}>0,10)$ dos níveis de treonina sobre o CRD.

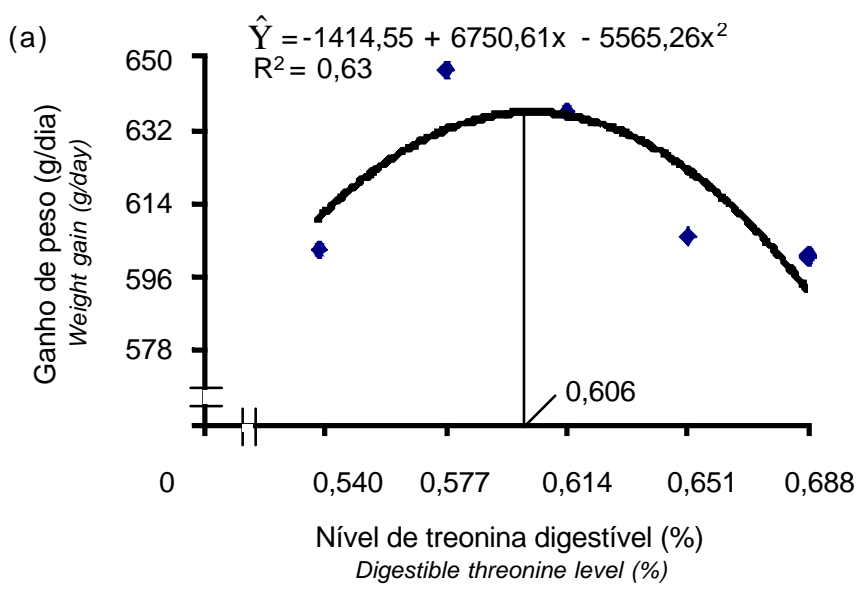

(b)

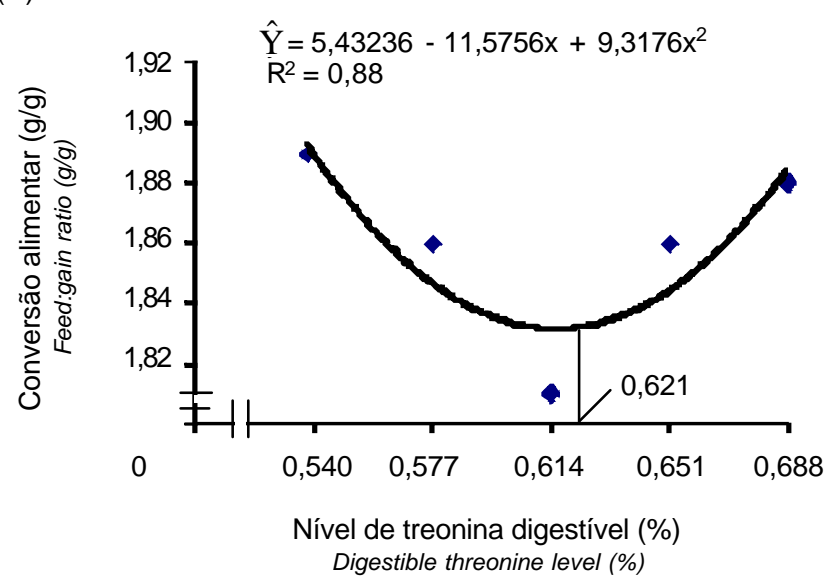

Figura 1 - Ganho de peso (g/dia) (a) e conversão alimentar $(\mathrm{g} / \mathrm{g})(\mathrm{b})$ de leitoas dos 15 aos $30 \mathrm{~kg}$, mantidas em ambiente termoneutro, em função do nível de treonina digestível da ração.

Figure 1 - Weight gain (g/day) and feed:gain ratio $(\mathrm{g} / \mathrm{g})$ of gilts from 15 to $30 \mathrm{~kg}$ kept in thermoneutral environment in function of the dietary digestible threonine level. 
Efeito quadrático do nível de treonina da ração sobre a CA de suínos em fase inicial de crescimento também foi observado por Pozza et al. (1999) e Berto et al. (2002), que estimaram, respectivamente, em $0,63 \%$ (leitões dos 15 aos $30 \mathrm{~kg}$ ) e $0,76 \%$ (leitões dos 12 aos $23 \mathrm{~kg}$ ) os níveis de treonina total que promoveram os melhores valores de CA.

As relações treonina digestível:lisina digestível estimadas neste estudo, de $67 \%$ para melhor resultado de CA e de $65 \%$ para máximo ganho de peso, foram semelhantes às de 67 e $66 \%$, respectivamente, recomendada por Rostagno et al. (2000) e Wang \& Fuller (1990) e superiores à de 63\% proposta por Rhodimet (1993). Constata-se que o nível de treonina para se obter a melhor eficiência de utilização do alimento pelo suíno é maior que aquele necessário para maximizar o ganho de peso, o que está consistente com os resultados obtidos por Rosell \& Zimmerman (1985) e Defa et al. (1999).

O nível de treonina digestível da ração propiciou variação quadrática $(\mathrm{P}<0,01)$ nas deposições de proteína (DP) e gordura (DG) na carcaça dos animais, que aumentaram até os níveis estimados de 0,608 e 0,609\%, respectivamente (Figuras 2a, b).

Variação da DP na carcaça de suínos na fase inicial de crescimento, em razão do nível de treonina da ração, também foi observada por Adeola (1995). No entanto, estes resultados diferem dos obtidos por Rodrigues et al. (2001), que não constataram efeito dos níveis de treonina da ração sobre a deposição de proteína de suínos na fase inicial de crescimento. A variação genética dos animais utilizados nos estudos pode consistir em um dos principais fatores responsáveis pela diferença de resposta de DP dos animais ao nível de treonina da ração. De acordo com dados obtidos Thong \& Liebert (2004), a exigência de treonina dos animais varia de acordo com a capacidade genética para deposição de proteína dos animais.

O aumento de DP até o nível de 0,608\% de treonina justifica a melhora gradativa ocorrida no GPD, entre os níveis de 0,538 e $0,606 \%$. Estes resultados não confirmam o relato de De Blas et al. (1999) de que a exigência de treonina para máximo crescimento de tecido magro seria maior que aquela estabelecida para melhor resposta de ganho de peso.

Os resultados referentes à DG na carcaça dos animais contrastam com os de Taylor et al. (1982), Adeola (1995) e Rodrigues et al. (2001), que observaram redução da DG em função de níveis crescentes de treonina da ração.

Apesar do aumento $(\mathrm{P}<0,01)$ de $21 \%$ verificado no consumo de treonina digestível entre os tratamentos $(0,538$ e $0,68 \%)$, não se verificou efeito $(\mathrm{P}>0,10)$ dos níveis de

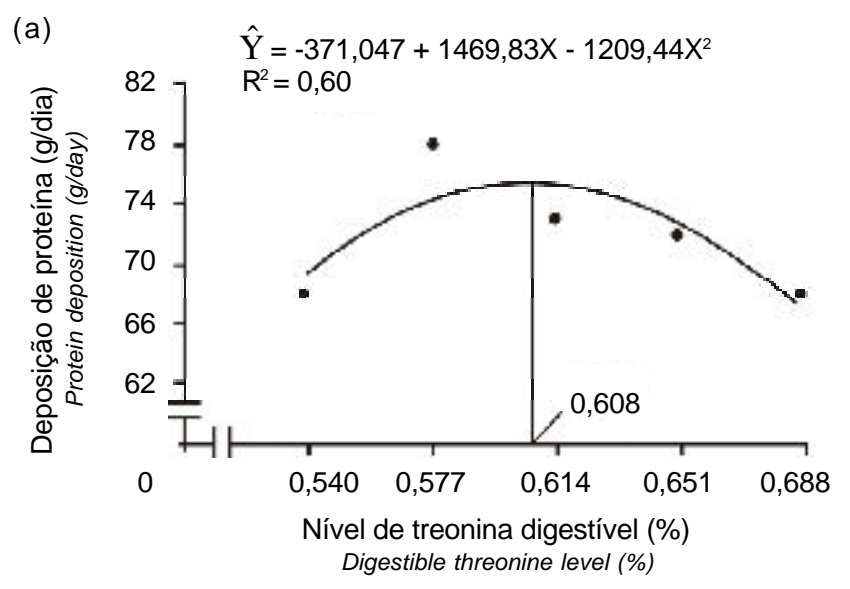

(b)

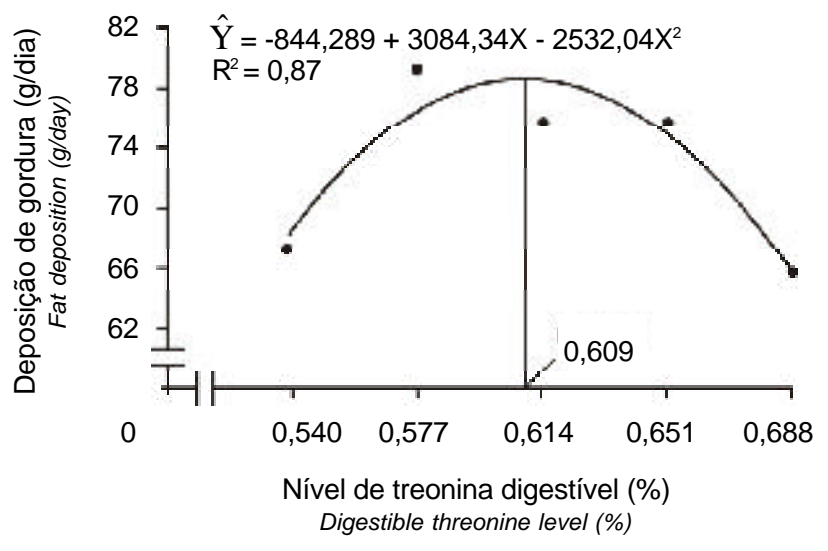

Figura 2 - Deposições (g/d) de proteína (a) e gordura (b) na carcaça de leitoas dos 15 aos $30 \mathrm{~kg}$ mantidas em ambiente termoneutro, em função do nível de treonina da ração.

Figure 2 - Protein (a) and fat (b) deposition rates $(\mathrm{g} / \mathrm{d}$ ) in the carcass of gilts from 15 to $30 \mathrm{~kg}$ kept in thermoneutral environment in function of the dietary digestible threonine level.

treonina digestível da ração sobre os pesos absoluto e relativo do fígado e dos rins (Tabela 3 ).

Esses dados contrastam com os obtidos por Chen et al. (1998), Hannas et al. (2000) e Le Bellego \& Noblet (2002), que observaram efeito do aumento dos níveis de proteína bruta e, ou, aminoácidos sobre os órgãos de suínos em fase inicial de crescimento. Considerando que o fígado e os rins são órgãos que alteram o seu metabolismo e, conseqüentemente, seu peso, por estarem diretamente envolvidos no catabolismo do excesso de aminoácidos (D’Mello, 1994), pode-se inferir que, provavelmente, o perfil de aminoácidos das rações experimentais utilizados neste estudo estavam mais ajustados que o das rações dos autores referenciados.

Os pesos absoluto e relativo de intestino aumentaram, de forma linear, com os níveis de treonina digestível da ração, segundo as equações $\hat{Y}=584,098+548,972 X$ 
Tabela 3 - Peso de órgãos de leitoas abatidas aos $30 \mathrm{~kg}$, mantidas em ambiente termoneutro, em função do nível de treonina digestível da ração

Table 3 - Weight of organs of gilts slaughtered at $30 \mathrm{~kg}$, kept in thermoneutral environment, in function of digestible threonine level in the diet

\begin{tabular}{|c|c|c|c|c|c|c|}
\hline \multirow[t]{2}{*}{ Item } & \multicolumn{5}{|c|}{$\begin{array}{c}\text { Nível de treonina digestível }(\%) \\
\text { Digestible threonine level }\end{array}$} & \multirow[t]{2}{*}{$\mathrm{CV}(\%)$} \\
\hline & 0,538 & 0,577 & 0,614 & 0,651 & 0,688 & \\
\hline & \multicolumn{5}{|c|}{$\begin{array}{l}\text { Peso absoluto }(\mathrm{g}) \\
\text { Absolute weight }(\mathrm{g})\end{array}$} & \\
\hline Fígado (Liver) & 706 & 721 & 683 & 689 & 707 & 7,4 \\
\hline \multirow[t]{3}{*}{ Intestino $^{1}$ (Intestine) } & 882 & 894 & 931 & 935 & 964 & 5,9 \\
\hline & \multicolumn{5}{|c|}{ Peso relativo $(\%)$} & \\
\hline & \multicolumn{5}{|c|}{ Relative weight (\%) } & \\
\hline Fígado (Liver) & 3,25 & 3,36 & 3,19 & 3,29 & 3,27 & 6,8 \\
\hline Rins(Kidneys) & 0,58 & 0,67 & 0,58 & 0,57 & 0,63 & 8,1 \\
\hline Intestino $^{2}$ (Intestine) & 4,07 & 4,15 & 4,37 & 4,38 & 4,47 & 5,4 \\
\hline
\end{tabular}

1 e 2 Efeito linear $(P<0,03)$ e $(P<0,01)$, respectivamente $($ Linear effect $[P<0.03]$ and $[P<0.01]$, respectively).

$\left(\mathrm{r}^{2}=0,84\right) ; \hat{\mathrm{Y}}=2,59085+2,76711 \mathrm{X}\left(\mathrm{r}^{2}=0,84\right)$, respectivamente. Ficou evidenciado que o desenvolvimento da mucosa intestinal é significativamente dependente do suprimento de treonina na dieta. Comprovando essa proposição, Bertolo et al. (1998) e Schaart et al. (2005), avaliando a utilização de treonina para leitões na fase inicial de crescimento, constataram que a exigência de treonina é substancialmente menor quando se fornece o alimento via parenteral em comparação ao fornecimento via enteral.

De acordo com Faure et al. (2005), entre os aminoácidos essenciais, a treonina é o mais importante para a mantença do trato gastrintestinal, posto que até $60 \%$ deste aminoácido na dieta é retido no intestino delgado dos suínos.

\section{Conclusões}

O nível calculado de $0,62 \%$ de treonina digestível, correspondente a uma relação com a lisina digestível de $67 \%$ e a um consumo diário de $7,11 \mathrm{~g}$, proporcionou melhor desempenho de leitoas mantidas em ambiente de conforto térmico dos 15 aos $30 \mathrm{~kg}$.

\section{Literatura Citada}

ADEOLA, O. Dietary lysine and threonine utilization by young pigs: efficiency or carcass growth. Canadian Journal of Animal Science, v.75, p.445-452, 1995.

BERTO, D.A.; WECHSLER, F.S.; NORONHA, C.C. Exigência de treonina de leitões dos 7 aos 12 e dos 12 aos $23 \mathrm{~kg}$. Revista Brasileira de Zootecnia, v.31, p.1176-1183, 2002.

BERTOLO, R.F.; CHEN, C.Z.; LAW, G. et al. Threonine requirement of neonatal piglets receiving total parenteral nutrition is considerably lower than that of piglets receiving an identical diet intragastrically. Journal of Nutrition, v.128, p.1752$1759,1998$.
BORG, B.S.; LIBAL, W.; WAHLSTROM, R.C. Tryptophan and threonine requirements of young pigs and their effects on serum calcium, phosphorus an zinc concentrations. Journal of Animal Science, v.64, p.1970-1078, 1987.

BRAGA, J.M. Avaliação da fertilidade do solo; ensaios de campo. Viçosa, MG: Universidade Federal de Viçosa, 1983. 101p.

BUFFINGTON, D.E.; COLAZZO-AROCHO, A.; CANTON, G.H. et al. Black globe-humidity index (BGHI) as comfort equation for dairy cows. Transaction of the ASAE, v.24, p.711-714, 1981.

CHEN, H.Y.; MILLER, P.S.; LEWIS, A.J. The effect of protein intake on the growth performance, plasma urea concentration, liver weight, and arginase activity of finishing barrows and gilts. Nebraska Swine Report, p.34-35, 1998.

DE BLAS, C.; GARCIA, A.I.; CARABAÑO, R. Necesidades de treonina en animales monogástricos. XVI Curso de Especialización - Avances en Nutrición y Alimentación Animal. Fundación Española para el Desarrollo de la Nutrición Animal: FEDNA. P.1-24, 2000.

DEFA, L.; CHANGTING, X.; SHIYAN, Q. et al. Effects of dietary threonine on performance, plasma parameters and immune function of growing pigs. Animal Feed Science and Technology, v.78, p.179-188, 1999.

D'MELLO, J.P.F. Amino acid imbalance, antagonism and toxicities. In: Amino acids in farm animal nutrition. [S. 1.: s. n.], 1994. p.63-97.

DONZELE, J.L.; COSTA, P.M.A.; ROSTAGNO, H.S. et al. Efeitos de níveis de energia digestíveis na composição da carcaça de suínos de cinco a quinze quilos. Revista Brasileira de Zootecnia, v.21, p.1100-1106, 1992.

FAURE, M.; MOËNNOZ, D.; MONTIGON, F. et al. Dietary threonine restriction specifically reduces intestinal mucin synthesis in rats. Journal of Nutrition, v.135, p.486-491, 2005.

HANNAS, M.I.; OLIVEIRA, R.F.M.; DONZELE, J.L. et al. Proteína bruta para suínos machos castrados mantidos em ambiente de conforto térmico dos 15 aos $30 \mathrm{~kg}$. Revista Brasileira de Zootecnia, v.29, p.476-484, 2000.

LE BELLEGO, L.; NOBLET, J. Performance and utilization of dietary energy and amino acids in piglets fed low protein diets. Livestock Production of Science, v.76, p.45-58, 2002.

LEWIS, A.J.; PEO JR., E.R. Threonine requirement of pigs weighting 5 to $15 \mathrm{~kg}$. Journal of Animal Science, v.62, p.1617-1623, 1986.

LEWIS, A.J. Amino acids in swine nutrition. In: LEWIS, A.J. (Ed.) Swine nutrition. 2.ed. Boca Raton: CRC Press, 2001. p.131-150. 
NATIONAL RESEARCH COUNCIL - NRC. Nutrient requirements of swine. 10.ed. Washington, D.C.: 1998. 189p.

PEDERSEN, C.; LINDBERG, J.E.; BOISEN, S. Determination of the dietary threonine:lysine ratio for finishing pigs using three different methods. Livestock Production Science, v. 82 p.233-243, 2003.

POZZA, P.C.; GOMES, P.C.; DONZELE, J.L. et al. Exigência de treonina digestível para suínos machos castrados dos 15 aos $30 \mathrm{~kg}$ Revista Brasileira de Zootecnia, v.28, p.560-568, 1999.

RHODIMET nutrition guide. Animal nutrition. 2.ed. France: Rhône-Poulenc, 1993. 55p

RODRIGUES, N.E.B.; DONZELE, J.L.; OLIVEIRA, R.F.M. et al Níveis de treonina em rações para leitões dos 6 aos $15 \mathrm{~kg}$. Revista Brasileira de Zootecnia, v.30, p.2033-2038, 2001.

ROSELL, V.L.; ZIMMERMAN, D.R. Threonine requirement of pigs weighing 5 to $15 \mathrm{~kg}$ and the effects of excess methionine in diets marginal in threonine. Journal of Animal Science, v.60, p.480-486, 1985.

ROSTAGNO, H.S.; ALBINO, L.F.T.; DONZELE, J.L. et al. Composição de alimentos e exigências nutricionais (Tabelas Brasileiras para Aves e Suínos). Viçosa, MG: Universidade Federal de Viçosa, 2000. 141p.

SALDANA, C.L.; KNABE, D.A.; OWEN, K.G. et al. Digestible threonine requirements of starter and finisher pigs. Journal of Animal Science, v.72, p.144-150, 1994.
SCHAART, M.W.; SCHIERBEEK, H.; van der SCHORR, S.R.D. et al. Threonine utilization is high in the intestine of piglets. Journal of Nutrition, v. 165, p.765-770, 2005.

SILVA, D.J. Análise de alimentos: métodos químicos e biológicos. Viçosa, MG: Universidade Federal de Viçosa, 1990. 166p.

STAHLEY, T. Nutrition effects lean growth, carcass composition. Feedstuffs, v.65, p.12, 1993

TAYLOR, A.J.; COLE, D.J.A.; LEWIS, D. Amino acid requirements of growing pigs. 3. Threonine. Animal Production, v.34, p.1-8, 1982

THONG, H.T.; LIEBERT, F. Potential for protein and threonine requirement of modern genotype barrows fed graded levels of protein with threonine as the limiting amino acid. Journal of Animal Physiology and Animal Nutrition, v.88, p.196203, 2004.

UNIVERSIDADE FEDERAL DE VIÇOSA - UFV.SAEG - Sistema para análises estatísticas e genéticas (Manual de utilização do programa). Versão 7.1. Viçosa, MG: 1997. 150p.

WANG, T.L.; FULLER, M.F. The effect of the plane of nutrition on the optimum dietary amino acid pattern for growing pigs. Animal Production, v.50, p.155-164, 1990.

Recebido: 25/1/2006 Aprovado: 30/5/2007 